\title{
HELPING BEHAVIOUR DURING COOPERATIVE LEARNING AND LEARNING GAINS: THE ROLE OF THE TEACHER AND OF PUPILS' PRIOR KNOWLEDGE AND ETHNIC BACKGROUND
}

This is a post-print of an article submitted for consideration in the Learning and Instruction (C) 2008 Elsevier.

Personal use of this manuscript is permitted. Permission from Elsevier must be obtained for any other commercial purpose.

This article may not exactly replicate the published version, due to editorial changes and/or formatting and corrections during the final stage of publication. Interested readers are advised to consult the published version which can be found at:

http://www.sciencedirect.com/science/article/pii/S0959475207000151

doi:\{10.1016/j.learninstruc.2007.01.014 \}

Please refer this manuscript as:

Oortwijn, M. B., Boekaerts, M., Vedder, P., \& Strijbos, J. W. (2008). Helping behaviour during cooperative learning and learning gains: The role of the teacher and of pupils' prior knowledge and ethnic background. Learning and Instruction, 18, 146-159. 
Running head: Helping behaviour during cooperative learning

\title{
Helping behaviour during cooperative learning and learning gains: The role of the teacher and of pupils' prior knowledge and ethnic background
}

\author{
Michiel B. Oortwijn, Monique Boekaerts, Paul Vedder, Jan-Willem Strijbos \\ Faculty of Social and Behavioural Sciences, Centre for the Study of Education and Instruction, Leiden \\ University, Wassenaarseweg 52, 2333AK Leiden, The Netherlands
}

\begin{abstract}
Is helping behaviour (i.e., solicited help and peer tutoring) during cooperative learning (CL) related to subsequent learning gains? And can teachers influence pupils' helping behaviour? One hundred one 5th grade pupils from multiethnic schools, 10-12 years old, participated in the study. Forty two pupils (31 immigrant) worked in an experimental condition, characterized by the stimulation of solicited high quality help and 59 (24 immigrant) worked in a control condition. It was found that learning gains were predicted positively by pupils' unsolicited helping behaviour (i.e., peer tutoring) and negatively by solicited help. Furthermore, teachers were able to affect pupils' low quality solicited help only. Lastly, immigrant pupils used less helping behaviour than local pupils, irrespective of CL setting.
\end{abstract}

Key words: Helping behaviour; Mathematical ability; Ethnicity; Cooperative learning.

\footnotetext{
${ }^{1}$ Tel.: +31 715273425 .

E-mail address: oortwijn@fsw.leidenuniv.nl (M. B. Oortwijn)
} 


\section{Introduction}

Often, during direct teaching in elementary schools there is little room for pupils to ask their classmates for help (Johnson \& Johnson, 1994). Pupils often are inclined to ask the teacher for help, since they view the teachers as more able to facilitate learning as compared to their peers (Newman \& Schwager, 1993). This is unfortunate since educational research has demonstrated that interactions between peers can augment their learning gains (e.g., Chinn, O’Donnell, \& Jinks, 2000; Gillies \& Ashman, 2000; Webb \& Mastergeorge, 2003). Thus, there is increased interest in the mechanisms that bring about effective peer interactions, that is, the constituents of peer interactions that are related to higher learning gains, the context factors that affect peer interactions, and the relation of peer interactions with learning gains (e.g., Fuchs, Fuchs, Kazdan, \& Allen, 1999; Gillies, 2004).

One of the most consistent findings in the literature is the positive effect of high quality verbal helping behaviour on learning gains (Gillies \& Ashman, 1997; King, 2002; Topping, 2005; Webb \& Farivar, 1994; Webb \& Mastergeorge, 2003). Following Webb and Mastergeorge (2003), high quality verbal helping behaviour is defined here as those utterances of peers that ask for explanations, give explanations, or apply them on the task at hand. In the present study we investigated how high quality helping behaviour during cooperative learning (CL) affects pupils' subsequent learning gains. Our study differs from that of Webb and Mastergeorge (2003) in that we investigated both solicited and unsolicited helping behaviour and additionally considered three factors that might mediate the relationship between high quality verbal helping behaviour and learning gains, namely the role of the teacher and the pupil background characteristics, such as ethnicity and prior knowledge.

\subsection{High quality helping behaviour}

Researchers of peer interactions and learning tend to use different concepts and distinctions when exploring peer interactions. For instance, Nelson-Le Gall and Clor-Scheib (1985) distinguished executive help seeking (i.e., asking for an answer) from instrumental help seeking (i.e., asking for an explanation). Vedder (1985) proposed that for instrumental help to be effective, the help receiver must understand the help given, have an opportunity to apply it, and actually apply it. Webb and her colleagues (Webb, Troper, \& Fall, 1995) integrated the aforementioned elements of solicited helping behaviour into an elaborate coding scheme that distinguished between high and low quality verbal helping behaviour in asking, giving, and applying help.

The effects of both solicited help giving and help receiving have been extensively studied. Studies have consistently reported that the help giver benefits from providing high quality solicited help (e.g., King, 2002; Webb \& Mastergeorge, 2003). King (2002) asserts that this is because it stimulates the help giver to elucidate and reorganize knowledge and to recognize mistakes. In a group setting, a learner who is explaining a concept to another learner has to 'tune' the help to the cognitive level of the receiver. Through the reorganization of the knowledge needed for the attuning, the learner who gives the explanation comes to understand the concept more thoroughly. Clearly, solicited high quality helping behaviour may also benefit the help receiver. Webb and Mastergeorge (2003) emphasize that high quality help is only useful to the receiver when it is sufficiently elaborated, correct, on time, and links up to the need for help. However, the most accurate predictor of learning gains is whether or not the help receiver applies the help that is given.

Not all help is asked for. Sometimes a pupil assumes the role of tutor, guiding the problemsolving process of another pupil, the tutee, by asking problem-solving questions or giving assignments that are aimed at solving the problem. We refer to this type of unsolicited helping behaviour here as peer tutoring. Topping (2005) showed in a review study that peer tutoring can increase the learning gains of both the tutor and the tutee. Most studies on peer tutoring have focused on cross-age peer tutoring and generally have provided support for a positive relation between peer tutoring and learning gains (Topping, Peter, Stephen, \& Whale, 2004). Van Keer and 
Verhaeghe (2005) suggested that the positive effect on reading performance was larger for crossage peer tutoring than for same-age peer tutoring. Topping et al. (2004) found that tutoring not only boosted the learning gains of the tutees, but also of the tutors. In their study, the cognitive ability of the tutors was roughly of the same level as that of the tutees. They concluded that same-age peer tutoring might be just as effective as cross-age peer tutoring for students' learning gains. However, they also suggested that peer tutoring is most effective if the participating students are free to be a tutor or a tutee, depending on the nature of the problem. This is in keeping with a study by Robinson, Schofield, and Steers-Wentzell (2003) who argued that cross-age tutoring makes it almost impossible to establish reciprocal tutoring and therefore is less effective than reciprocal same-age peer tutoring.

\subsection{Peer interactions during CL and learning gains}

\subsubsection{The teacher's role}

Teachers play an important role in CL. What they are doing and not doing affects the quality of pupils' problem-solving process considerably. Teachers who promote complex cognitive communication between pupils boost the quality of peer interactions and performance (Chinn et al., 2000; Gillies \& Ashman, 2000). However, teachers seem to have difficulties to teach pupils to use high quality helping behaviour (Gillies, 2003; Meloth \& Deering, 1999). A possible reason is a high task load for the teacher resulting from the requirements for CL (Turner, Meyer, Cox, Logan, DiCintio, \& Thomas, 1998). Specifically, teachers need to plan learning activities geared at the acquisition of content knowledge and new domain skills as well as learning activities that help students to cooperate effectively. Additionally, teachers need to guide the CL skills of both individual students and groups as a whole. Effectively and efficiently satisfying these combined requirements takes effort and time on the part of the teacher, which means that promoting effective CL is a long-term project (Webb, Nemer, \& Ing, 2006).

Gillies and Ashman $(1997,2000)$ demonstrated that when teachers do successfully stimulate high quality helping behaviour, pupils' communicative skills and performance are boosted: they found that pupils had higher learning gains, and their interactions were characterized by more high quality solicited helping behaviour and peer tutoring. Other studies have confirmed the positive effect of the stimulation of pupils' elaborated helping behaviour on their use of high quality helping behaviour (Fuchs et al., 1999) and peer tutoring (Nixon \& Topping, 2001).

\subsubsection{Student characteristics}

Several studies have shown that students' characteristics, such as ethnicity and prior knowledge, influence their helping behaviour and learning gains in a CL setting.

Ethnicity. In the Netherlands, there are three major discernable ethnic groups with respect to their performance at school: (a) Moroccan, Turkish, and Antillean youth, (b) Surinamese and other ethnic youth groups (e.g., Asian, former Yugoslavia), and (c) Dutch youth. Tesser and Iedema (2001) have shown that especially the performance of the Moroccan, Turkish, and Antillean groups falls behind. Research has revealed that the linguistic setback of these groups is a possible explanation of their low academic performance (Tesser \& Iedema, 2001; Vedder \& Horenczyk, 2006). Since these ethnic groups together form the majority of immigrant youth in the Netherlands, it may come as no surprise that the academic performance of pupils in multicultural schools falls below the national mean (Bosker \& Guldemond, 2004). However, a study by Webb and Farivar (1994) revealed that the implementation of CL can decrease the educational setback of immigrant pupils. They found that teachers who promoted pupils' use of solicited high quality helping behaviour boosted the solicited high quality helping behaviour of immigrant pupils and their mathematical setback was reduced, as compared to national pupils (see also Calderón, HertzLazarowitz, \& Slavin, 1998).

Prior knowledge. Several studies have shown that students with high prior knowledge are more able to stay focused on the group task and to plan and evaluate their actions (Hmelo, 
Nagarajan, \& Day, 2000; O’Donnell \& Dansereau, 2000). Puustinen (1998) argued that pupils with low prior knowledge are less able to self-regulate their learning, which heightens their need for structured group work and guidance by the teacher. Evidently, immigrant students in the Netherlands fall into this category of pupils.

\section{Aims - Hypotheses}

In this study we investigated how high quality verbal helping behaviour is related to learning gains in a CL setting. We were interested in how the interaction between ethnicity and prior knowledge with the teacher's role affects pupils' helping behaviour (both solicited and tutoring) and their subsequent learning. To assess the effect of solicited high quality helping behaviour on learning gains we constructed a CL curriculum that borrowed rules for solicited high quality helping behaviour from Webb and Farivar (1994) and Webb, Troper, and Fall (1995). We manipulated the role of the teacher: one group of teachers was required to stimulate pupils' solicited high quality helping behaviour (experimental condition), while the other group was required not to do this (control condition). Pupils' prior knowledge in mathematics was defined as "mathematical ability". Pupils were enrolled in ethnically diverse classrooms.

Our hypotheses were the following:

Both tutoring behaviour and high quality solicited verbal helping behaviour will be positively related to posttest mathematical performance (Hypothesis 1). National pupils will have an advantage over immigrant ones as regards the frequency with which they display tutoring behaviour and high quality solicited verbal helping behaviour because of the more limited linguistic proficiency of immigrant pupils (Hypothesis 2). Pupils in the experimental condition will use more high quality solicited verbal helping behaviour than in the control condition (Hypothesis 3). Following Webb and Farivar (1994) and Gillies and Ashman (2000), however, we expected that there will also be interactions of condition, ethnicity, and mathematical ability. Specifically, we predicted that immigrant pupils and pupils with low mathematical ability will display higher learning gains and more solicited high quality helping behaviour in the experimental condition. Also, national pupils with low mathematical ability will display more solicited high quality helping behaviour in the experimental condition as compared to immigrant pupils with low mathematical ability (Hypothesis 4).

\section{Method}

\section{1. Sample}

The total sample comprised 48 groups of 3 to 4 pupils each $(\underline{N}=166)$, from 10 classes of 5 th grade. Each teacher and his/her classroom were randomly assigned to the experimental or control condition. Ten teachers (nine Dutch, one immigrant; one male, nine female) participated in this study $(\underline{\mathrm{M}}=41$ years, $\underline{\mathrm{SD}}=8.6)$. Four of them were experienced teachers (i.e., teaching more than 10 years, two in the experimental and two in the control condition). Two CL lessons were video-recorded in order to gain a representative picture of the interactions of the pupils. Since we were only interested in the peer interactions, not in the teacher-pupil interactions, we selected only those recordings in which the peer interactions were not interrupted by the teacher. A subsample of 27 groups $(\underline{\mathrm{n}}=101)$ qualified for further analysis, consisting of 53 boys and 48 girls $(\underline{\mathrm{M}}=135.2$ months, $\underline{\mathrm{SD}}=6.4)$. The mean length of the two video recording episodes was 1372.4 seconds $(\underline{\mathrm{SD}}=$ 142.4) and did not differ between conditions.

Insert Table 1 about here

There were 12 groups in the control condition $(\underline{\mathrm{n}}=42)$ and 15 groups in the experimental condition $(\underline{\mathrm{n}}=59)$. The groups were narrow-heterogeneous in terms of mathematical ability (high- 
middle or low-middle) and were formed by the teacher and the researcher. As regards ethnicity, pupils were considered national when at least one parent was of Dutch origin and immigrant when both parents were of foreign origin. There were 11 national and 31 immigrant pupils in the control condition. In the experimental condition there were 35 national pupils and 24 were immigrant pupils (see Table 1). The majority of the immigrant pupils were of Moroccan or Turkish descent: $67 \%$ in the experimental condition and $87 \%$ in the control condition. Mathematical ability and linguistic proficiency were used as covariates in the analyses.

\subsection{Instruments}

As a manipulation check a teacher checklist on CL implementation and videotaped teacherpupil interactions was used. Pupil performance was assessed with a mathematical pre- and posttest, a linguistic proficiency test. Helping behaviour was assessed with a coding scheme for verbal peer interactions.

\subsubsection{Teacher checklist on CL implementation}

Teachers rated on a 4-point Likert-scale ( 1 = 'very often' and $4=$ 'very little') the extent to which they had implemented a number of CL rules. A principal component analysis with varimax rotation revealed a three-factor solution. The solution explained $71 \%$ of the variance. All factor loadings were higher than .50 . The first factor (18 items, Cronbach's $\underline{\alpha}=.97)$ comprised statements about general CL rules (e.g., "I teach the children not to interrupt each other"). The second factor (5 items, Cronbach's $\underline{\alpha}=.81$ ) referred to the rules for giving help and receiving help (e.g., "I teach the children to keep asking when someone poses an unclear question'). The third factor (4 items, Cronbach's $\underline{\alpha}=.84$ ) regarded the feedback on the CL process (e.g., "At the end of each lesson I discuss with each group what is going well and what should be improved'). Each teacher completed the checklist at the end of every other mathematical lesson, starting at the first lesson, amassing five checklists in total.

\subsubsection{Videotaped teacher-pupil interactions}

All teachers were videotaped during two, randomly selected, lessons. The teachers were not told in advance which CL lessons we would videotape. All recordings were rated by two independent scorers, one of whom was double blind to the experimental manipulation. The coders filled in a coding scheme of 14 items. A principal component analysis with varimax rotation was applied; $62 \%$ of the variance was explained. All factor loadings were .50 or higher. The first factor (6 items, Cronbach's $\underline{\alpha}=.71$ ) concerned whole-class reflection on the group work (e.g., "Did the teacher reflect on group performance in the prior lesson?'). The second factor ( 8 items, Cronbach's $\underline{\alpha}=.86$ ) regarded the teacher's activities during the group work (e.g., "Did the teacher encourage group members to ask each other questions?"). The items were rated on 3-point Likert-scale $(1=$ 'little' and 3 = 'often'). The inter-coder reliability (calculated over two recordings, approximately ten percent of the total number) was satisfactory: for Factor 1 kappa $=.73$ and for Factor 2 kappa $=$ .62 .

\subsubsection{Mathematical ability}

Scores from a curriculum-independent mathematical test by the Central Institute for Test Research (CITO; Janssen, Kraemer, \& Noteboom, 1996) were used to assess the baseline mathematical performance of all pupils. The teachers scored the test for all pupils. Previous research has shown that CITO has a good internal consistency, Cronbach's $\underline{\alpha}=.94$ (Evers, Van Vliet-Mulder, \& Groot, 2000).

\subsubsection{Mathematical posttest}

The mathematical posttest consisted of multiple choice items that assessed general knowledge of area, scale, fractions, percentage, and circle diagrams. A reliability analysis of the 
data obtained in this study revealed that the internal consistency was satisfactory, Cronbach's $\underline{\alpha}=$ .75. A previous study demonstrated that the mathematical posttest significantly correlated with CITO, $\underline{\mathrm{r}}=.77, \underline{\mathrm{p}}<.001$ (Oortwijn, Boekaerts, \& Vedder, 2005).

\subsubsection{Linguistic proficiency}

This test was taken from the National Testing Service, used to assess pupils' learning progress in elementary schools (Janssen et al., 1996). The scores of the two dimensions of the test, namely vocabulary and reading comprehension, were averaged in our study into the new variable linguistic proficiency. This variable was used to determine whether pupils' language proficiency affected their helping behaviour. Thus, it was used as relevant background characteristic of the pupils.

Insert Table 2 about here

\subsubsection{Coding of verbal peer interactions}

The coding scheme of Webb and Mastergeorge (2003) on solicited verbal help was adapted to suit the needs of this study. The resulting coding scheme was made up of four categories (see Table 2). Webb and Mastergeorge (2003) discussed the relationship of both help giving and help receiving with learning gains and investigated the relationship of help receiving with learning gains. We investigated both relationships.

Category 1, need for help, was composed of two subcategories: (a) request for an answer (low quality questions); it comprised request for information, e.g., "What is the answer to this one?", and general request for help, e.g., "I don't get it" (see also Webb, Ing, Kersting, and Nemer (2006) for a discussion of help that is not indicated by a question). (b) request for an explanation (high quality questions).

Category 2 targeted the level of verbally provided help by the help giver. It was composed of two subcategories: (a) low quality help, comprising unclear help, undesired help, and (numerical) outcome only, and (b) high quality help (explanation with a (part of a) problem-solving step).

Category 3 , constructive activity on the current problem by the help receiver, was composed of two subcategories: (a) low quality constructive activity, that is, no reaction and acknowledgement of the help received and copying the provided (numerical) outcome, and (b) high quality constructive activity, that is, working out part of a problem-solving step and working out one problem-solving step.

We excluded the category constructive activity on the next problem from our study. Since authentic, open-ended mathematical tasks were used, none of them were truly independent from each other. Therefore, no satisfactory distinction could be made between the current and the next problem. However, we added another category (Category 4) that assessed the frequency of peer tutoring by counting the number of tutor actions. Tutor actions were defined as unsolicited utterances aimed at stimulating a group member to give a problem-solving oriented response by asking a question, giving an assignment, or giving help. In the experimental condition, we only manipulated solicited help, not peer tutoring, and had no pre-set idea of which pupils should be tutors frequently and which pupils would be frequent tutees. A pupil action was scored as tutoring when (a) a tutor asked a problem-solving oriented question, or gave a problem-solving oriented assignment, or explanation, and (b) the tutee gave a problem-solving oriented response - see also the example in Table 2. We marked for each tutor action which pupil took on the role of tutor and which pupil(s) assumed the role of tutee (see Appendix for an example).

The inter-coder reliability was calculated on six recordings (approximately $10 \%$ of the total sample) between two observers (the first author and a second coder, unfamiliar with the study). For Category 1 the agreement between the two coders was 83\%, and kappa was .73. For Category 2, the agreement was $76 \%$, and kappa was .60. The agreement was $72 \%$ for Category 3, and kappa was also .60. For Category 4 (unsolicited help), the agreement was $88 \%$ and kappa was .76. In a number 
of cases (5\% of all utterances) one or both of the coders found an utterance to be impossible to be coded. These utterances were removed from the dataset for both coders (pair wise deletion). The second coder, who was blind to the manipulation, individually scored all the videotaped peer interactions.

\subsection{Procedure}

\subsubsection{CL training}

During a two-hour workshop the first author explained the essentials of effective CL to the teachers and instructed them how to implement it in the classroom. Subsequently, the teachers trained their pupils in two lessons how to effectively work in groups. In the first lesson general social CL rules were discussed and practiced. These rules required pupils to check whether: "everyone cooperates", 'everyone listens to each other', "everyone shares their knowledge and opinions", and "everyone agrees". In the second lesson more specific CL rules were discussed and practiced. Adapted from Webb and Farivar (1994), these rules were about high quality helping behaviour. Regarding receiving help, pupils were instructed to (a) ask precise questions, (b) continue asking in case of ambiguities, (c) think before asking a question, and (d) ask for help on time. With respect to giving help, pupils were instructed to (a) fine-tune the level of help to the need for help that is being requested, (b) give a clear and precise answer, (c) let the help receiver apply the help that is given, (d) continue to ask if the question for help is unclear, and (e) give help when needed.

\subsubsection{CL mathematical curriculum}

The CL mathematical curriculum consisted of nine one-hour lessons followed by a mathematical exam. The teachers in the control condition were required not to intervene in pupils' interactions. They were instructed only to interact with the pupils to tell them to talk less loudly (and not disturbing other groups), to listen to each other, or to stop making fun of each other. Teachers in the experimental condition were instructed to stimulate pupils' solicited high quality helping behaviour, as specified in the second lesson of the CL training, and to promote their use of general CL rules of the first lesson as much as possible. Lesson-to-lesson protocols were used to help the teachers implement CL in their condition (experimental and control condition).

The mathematical assignments used in this CL curriculum were authentic mathematical assignments. These are mathematical tasks with a strong narrative structure and which are embedded in contexts familiar to the children, such as calculating the area of classrooms in their school. They dealt with area, scale, fractions, percentage, and circle diagrams. All mathematical assignments were adjusted for CL purposes using authentic mathematical assignments from the regular mathematical curriculum. Pupils worked on two assignments per lesson.

During two randomly selected lessons - one somewhere at the beginning (Lesson 1-5) and one near the end of the CL curriculum (Lesson 7-9) - video recordings were made of the peer interactions in both the experimental and the control condition. After the CL mathematical curriculum all pupils individually completed a mathematical exam.

\section{Results}

We start with the manipulation check. Regarding the teacher checklist, we found that teachers in the experimental condition reported instructing pupils more in the use of helping behaviour throughout the CL curriculum, $\underline{\mathrm{t}}(21)=-3.37, \underline{\mathrm{p}}<.005$, than the teachers in the control condition, with a large effect size, Cohen's $\underline{\mathrm{d}}=1.48$. Remarkably, no differences were found on general CL rules and on extent of feedback on the CL process.

Regarding the videotaped teacher-pupils interactions we found that teachers in the experimental condition elaborated more on the group work at the start and the end of the lesson than 
teachers in the control condition, $\underline{\mathrm{t}}(16)=-1.78, \underline{\mathrm{p}}<.05$, which equates to a moderate effect size, Cohen's $\underline{\mathrm{d}}=.58$. No differences were found for the factor CL activities during group work.

\subsection{Hypothesis 1}

\subsubsection{Analyses at the individual level}

Hierarchical regression analyses of the performance of the individual pupils were employed to investigate whether peer tutoring and high quality solicited helping behaviour predicted subsequent mathematical performance. The predictor variables were ethnicity, condition, mathematical ability, requests for explanations, number of tutor actions provided by the tutor, number of tutor actions received by the tutee, high quality help, and high quality constructive activity. Posttest mathematical performance was the criterion variable (see Table 3 ). The analysis showed that mathematical ability was the main predictor of posttest mathematical performance. Of the other variables entered in Step 2 mathematical ability and requests for explanations were significant predictors. Requests for explanations were negatively associated with posttest mathematical scores. Remarkably, inclusion of the variables Condition and Ethnicity in the equation did not significantly changed the explained variance.

Insert Table 3 about here

In a similar hierarchical regression analysis, in which the Number of Tutor Actions Provided by the Tutor and Number of Tutor Actions Received by the Tutee instead of Requests for Explanations were included, only a positive relation between Number of Tutor Actions Provided by the Tutor and posttest mathematical performance was found. After Step 2, mathematical ability and the number of tutor actions provided by the tutor were positively predicting posttest mathematical performance (see Table 4).

Insert Table 4 about here

\subsubsection{Analyses at the group level}

We performed analyses at the group level in an attempt to corroborate the findings we found at the individual level. A number of researchers have suggested that more valid conclusions on learning in a social setting can be drawn when one takes into account multiple analytical perspectives (e.g., Rogoff, 1995). Due to the small sample size, the relationship of helping behaviour with posttest mathematical performance could not be evaluated with a multi-level approach. Inspired by earlier studies using a similar approach (Gillies \& Ashman, 2000; Webb \& Farivar, 1994), we conducted analyses at the group level by aggregating individual scores for each team.

The variable Group Level Tutoring Behaviour was created as the mean number of tutor actions provided by the tutors in each group. The variable had a severe skewness and kurtosis. A logarithmic transformation reduced the kurtosis and skewness to a value $<1$, which is acceptable (DeCarlo, 1997). Partial correlations were calculated for requests for explanations and group level tutoring behaviour, corrected for mathematical ability. We found a negative trend for requests for explanations $(\underline{\mathrm{M}}=1.65, \underline{\mathrm{SD}}=1.34), \underline{\mathrm{r}}=-.36, \mathrm{p}<.08$ (two-tailed). No relationship was found between group level tutoring behaviour and posttest mathematical performance. However, when we selected only those groups with a high number of tutor actions (i.e., at least one tutor action per group member, $\mathrm{n}=10$ ), we did find a positive trend, provided we corrected for mathematical ability $(\underline{\mathrm{M}}=.57, \underline{\mathrm{SD}}=.44), \underline{\mathrm{r}}=.63, \underline{\mathrm{p}}<.07$ (two-tailed).

\subsection{Hypothesis 2}


The linguistic proficiency of the immigrant pupils was lower than that of the national pupils, $\underline{\mathrm{t}}(88)=3.46, \underline{\mathrm{p}}=.001$. We explored whether the lower linguistic proficiency of the immigrant pupils was related to the use of tutor actions. We expected that if national pupils provided more tutor actions than immigrant pupils, this would be related to a more limited linguistic proficiency of immigrant pupils. An independent samples t-test revealed a significant effect, $\underline{t}(21)=2.89, \underline{p}<.01$. A Mann-Whitney test corroborated this finding, $\underline{Z}(21)=-2.42, \underline{p}<.02$. National pupils who provided tutor actions had a higher linguistic proficiency than immigrant tutors.

\subsection{Hypothesis 3 and 4}

We carried out a 2(condition) x 2(ethnicity) MANCOVA to analyze the relationship of condition with high quality solicited helping behaviour. Mathematical ability was the covariate. Additionally, we carried out a regression analysis to investigate the effect of the interaction Condition x Mathematical ability and the interaction Ethnicity x Mathematical ability on high quality solicited helping behaviour.

\subsubsection{Analyses at the individual level}

In the above MANCOVA the dependent variables were the seven categories of the coding scheme (i.e., request for an answer, request for an explanation, low and high quality of provided help, low and high quality constructive activity, and tutor actions).

Insert Figure 1 about here

No main effects were found for condition and ethnicity, although there was a trend for condition. We found a 2-way interaction effect for the relation of condition and ethnicity with the level of verbally provided help, Wilks' Lambda $=.89, \underline{\mathrm{F}}(2,95)=5.76, \underline{\mathrm{p}}<.005, \underline{\eta}^{2}=.11$. National pupils in the control condition provided more low quality help than immigrant pupils, $\underline{F}(1,38)=$ $4.94, \underline{p}<.04, \underline{\eta^{2}}=.12$ (see Figure 1). In the experimental condition no such difference was found. Regarding low and high quality constructive activity and tutoring no effects were found.

We conducted a regression analysis to test the impact of the Mathematical ability $\mathrm{x}$ Condition and Mathematical ability $\mathrm{x}$ Ethnicity interactions (predictor variables) on the categories of the coding scheme (criterion variables). To compensate for effects of multiple testing, we used a stricter alpha $(\underline{\alpha}=.01)$. No effects were found on the subcategories of Need for Help. In the subcategories of Level of Verbally Provided Help, the interaction Ethnicity x Mathematical ability explained 17\% of the variance of high quality help, $\underline{\beta}=-.42$, $\underline{\mathrm{t}}(43)=-2.79, \underline{\mathrm{p}}<.01$ (see Table 5). Immigrant pupils with low mathematical ability provided more high quality help than national pupils with a low one. Immigrant pupils with medium to high mathematical ability provided less high quality help than national pupils with a medium to high one. Regarding the subcategories of Constructive Activity on the Current Problem the interaction of ethnicity with mathematical ability explained $19 \%$ of the variance in low quality constructive activity, $\underline{\beta}=-.36, \underline{\mathrm{t}}(67)=-3.08, \underline{\mathrm{p}}<.004$. Immigrant pupils with low mathematical ability showed more low quality constructive activity than the respective national pupils. In contrast, immigrant pupils with medium to high mathematical ability showed more low quality constructive activity than the respective national pupils. We found no relations between the aforementioned criterion variables and tutoring (Category 4).

Insert Table 5 about here

\subsubsection{Analyses at the group level}

We investigated whether the interaction effect of ethnicity and condition with low quality help that we found at the individual level was maintained at the group level. We recoded ethnicity into a group-level variable: we considered a group national if there was one or no immigrant pupil 
present and we regarded a group as immigrant when there was one or no national pupil in the group. The groups with an even distribution of immigrant and national pupils $(\underline{n}=4)$ were left out of the group level analyses. We conducted an ANCOVA analysis in order to examine whether we could support the two-way interaction effect of condition and ethnicity with low quality help, corrected for mathematical ability, which we found at the individual level. The group level analysis corroborated the 2-way interaction effect we found at the individual level, $\underline{F}(1,18)=6.63, \underline{p}<.02$, $\underline{\eta^{2}}=.27$. National groups provided more low quality help in the control condition than immigrant groups. We could not confirm the relation between mathematical ability and ethnicity with high quality help and low quality constructive activity which we found in the analyses at the individual level.

\subsection{Summary of the findings}

The frequency of requests for explanations was negatively related to posttest mathematical performance and the number of tutor actions provided by the tutor was positively related to posttest mathematical performance, both at the individual and the group level. These findings partly support Hypothesis 1. In addition, we found that national pupils provided more tutor actions than immigrant pupils. This was associated most notably with a lower linguistic proficiency of immigrant tutors, as Hypothesis 2 predicted. Hypothesis 3, however, that predicted a condition effect on high quality helping behaviour was not verified. Instead there was an interaction of condition with ethnicity and mathematical ability as Hypothesis 4 predicted. National pupils in the control condition provided more low quality help than immigrant pupils. This finding was corroborated at the group level. Analyses at the individual level further showed that, regardless of condition, immigrant pupils with low mathematical ability provided more high quality help and used more low quality constructive activity than their national counterparts. In contrast, immigrant pupils with medium to high mathematical ability provided less high quality help and used less low quality constructive activity than their national counterparts.

\section{Discussion}

The finding that the number of tutor actions provided by the tutor was positively related to subsequent mathematical performance of the tutor is in line with other studies that also pointed out the significance of peer tutoring in CL (Duran \& Monereo, 2005; Gillies \& Ashman, 1997, 2000; Topping, 2005). Topping (2005) suggested that for peer tutoring to be effective for both the tutor and the tutee, it has to be stimulated by the teacher. However, our instructions to the teachers specifically targeted the solicited helping behaviours and not peer tutoring. On the other hand, the study of Duran and Monereo (2005) suggests that peer tutoring is most successful when the tutor and tutee interact on an equal or reciprocal basis. A stronger relation between peer tutoring and posttest mathematical performance might have been found if the teachers had been instructed to stimulate reciprocal tutoring.

This study also demonstrated that pupils do not have to be the best in mathematics to be successful tutors. There is mounting evidence that peer tutoring is most successful when the tutor and tutee cognitively challenge each other, meaning that their cognitive abilities are roughly the same (Topping, 2005; Topping et al., 2004). The fact that national pupils assumed the role of tutor more often might have to do with their higher linguistic proficiency. It might also be related to their willingness to assume the tutor role.

We found no relationship of provided high quality help and high quality constructive activity with subsequent mathematical performance. A reason could be a transfer problem. In the present study, and different from the Webb and Mastergeorge (2003) study, the mathematical posttest contained problems that were meant to be different from the type of assignments that the pupils completed during the CL lessons. Webb and Mastergeorge (2003) used a program-dependent mathematical test, whereas we used a mathematical test that was more general and program- 
independent. A second reason might be pupils' lack of CL experience. Limón (2001) suggested that minimal prior CL knowledge hampers productive participation in CL. Our study showed that pupils had minimal experience with and knowledge of CL. It is possible that the pupils adopted the solicited low quality helping behaviour when solving a mathematical assignment because they were more comfortable with it. Other studies also reported that teachers are less successful in increasing high quality helping behaviour if pupils lack the skills for high quality peer interactions (Prichard, Stratford, \& Bizo, 2006). In addition to a lack of CL experience, the mathematical tasks may have been too complex (both linguistically and mathematically) for the pupils - of whom a significant part had both a linguistic and a mathematical setback - resulting in a cognitive overload. Research by Pollock, Chandler, and Sweller (2002) has suggested that pupils who lack the necessary skills to solve complex tasks (i.e., linguistic and mathematical low-achievers) are prone to a cognitive overload. These pupils might be helped more with a highly structured direct teaching setting (see also Tesser \& Iedema, 2001).

Regarding the teacher's role during CL we found that teachers were unable to stimulate pupils' high quality helping behaviour, although they were successful in reducing low quality helping behaviour. Three reasons are put forward here for this finding. First, the CL curriculum was not long enough. Researchers have demonstrated that teaching pupils to use high quality helping behaviour is a long-term, time consuming process (Cohen, 1994; Webb et al., 2006). Nevertheless, an earlier study (Webb \& Farivar, 1994) did reveal that the teachers were able to stimulate pupils' solicited high quality helping behaviour on a relatively short term. These researchers implemented a CL mathematical curriculum that covered ten weeks and audiotaped the peer interactions in the eighth week. This differs from our study, in which we videotaped the peer interactions of each group twice, the first near the beginning and the second near the end of the CL curriculum. We did this in order to gain a more representative picture of the frequency of the occurrence of the (sub)categories of the coding scheme. It is plausible that we could not corroborate Webb and Farivar's (1994) results because the children were not yet familiar with the use of high quality helping behaviour during the first video recording.

Second, teachers in the experimental condition reported instructing their pupils more in the use of solicited high quality helping behaviour than in the control condition. Nevertheless, observation of videotaped teacher-pupil interactions revealed that the teachers only instructed their pupils in the use of solicited high quality helping behaviour at the beginning and end of the group work; not during the group work. Why did the teachers not give CL feedback when the pupils required it? It might be that the teachers did not accurately perceive the effectiveness of their own CL activities. Earlier studies have made similar suggestions (e.g., Vedder \& Veendrick, 2003). Indeed, researchers have suggested that teachers are not well equipped to implement effective CL (e.g., Gillies, 2003). It could also be that, although the teachers in this study were given detailed instructions (both orally and in written form), individual differences in teaching style blurred differences between the two conditions. Previous studies have suggested that teaching style is hard to change (see Gill, Ashton, \& Algina, 2004 for a more detailed discussion), which might well mean that changing the teaching style in order to let teachers implement more effective CL takes longer than the 11 lessons this CL curriculum consisted of.

The third reason, which is related to the second, regards the lack of experience of both the pupils and the teachers with CL. Webb et al. (2006) pointed out that pupils tend to copy teacherpupil interactions in their own interactions with fellow group members. When a lack of CL experience results in the teachers not instructing pupils properly in the use of helping skills and in giving no example of good practice, pupils are likely to model behaviour that is poor on examples of help giving. This might explain why we found no difference between the two conditions both with respect to the instruction of solicited high quality help by the teacher and the use of solicited high quality help by the pupils. The aforementioned finding suggests that further research is warranted to investigate how teacher background characteristics (e.g., experience with CL) affect the effectiveness of their teaching behaviour during CL. 
Finally, we found mixed results for the role of ethnicity in helping behaviour. We could not find support for our hypothesis that immigrant pupils with low mathematical ability would use less high quality helping behaviour than the respective national pupils. However, we did find that the immigrant pupils in general incorporated less verbal helping behaviour in their communication. These findings are in line with other studies suggesting that immigrant pupils are less actively involved in group work (e.g., Kirchmeyer, 1993). In our study we found that this was due most notably to a lower linguistic proficiency of immigrant pupils as compared to national pupils.

\subsection{Limitations}

It is conceivable that the frequency of high quality help is higher when the pupils are accustomed to CL. Thus, if we had videotaped two lessons at the end of the CL curriculum we might have found more pronounced differences in high quality helping behaviour between the experimental and the control condition. Also, the immigrant pupils were overrepresented in the control condition where in fact they formed the majority. This might have affected the results, although it is important to point out here that the immigrant pupils in the control condition did not differ from the immigrant pupils in the experimental condition with regard to their use of helping behaviour.

\subsection{Conclusion}

Earlier studies have shown that the stimulation of high quality helping behaviour during CL is associated with higher learning gains. Our study suggests, however, that incorporating high quality helping behaviour in CL not only strains pupils' cognitive capacities, but also places high demands on teacher behaviour. It is recommended that future studies implement training programs that take into account relevant background characteristics of both pupils and teachers (see also Webb et al., 2006). Additionally, the data revealed that, although pupils were not trained in the use of peer tutoring, there was a positive relation between peer tutoring and posttest mathematical performance. This suggests that peer tutoring requires less training than solicited high quality help and is better suited to augment mathematical performance. Moreover, peer tutoring may be more effective to reduce pupils' educational setback.

\section{Appendix. Example of a coded interaction fragment}

\begin{tabular}{|c|c|c|}
\hline Utterance & & Coded category \\
\hline Pupil V & O!, can I use your ruler, I don’t have one. & $\begin{array}{l}\text { Organizational utterance (not } \\
\text { used in the analyses) }\end{array}$ \\
\hline Pupil B & $\begin{array}{l}\text { Sure. Do you know what to do now? This is } \\
8.5 \text { and this is } 19 \text {, ok? So } 8 \text { and a half times } 2 \\
\text { is } 19 \text {. So you have to write } 8.5 \text { centimetres } \\
\text { here and } 19 \text { here, ok? (shows on work sheet } \\
\text { of V) }\end{array}$ & Tutoring behaviour \\
\hline Pupil V & $\begin{array}{l}\text { Yes, so I have to write here } 8.5 \text { centimetres } \\
\text { first. }\end{array}$ & $\begin{array}{l}\text { Low quality constructive } \\
\text { activity }\end{array}$ \\
\hline Pupil B & $\begin{array}{l}\text { No! No, don't write. You have to do } 8.5 \\
\text { centimetres in length and } 19 \text { centimetres in } \\
\text { width. }\end{array}$ & Tutoring behaviour \\
\hline Pupil V & Yes... (starts calculating) & $\begin{array}{l}\text { Low quality constructive } \\
\text { activity }\end{array}$ \\
\hline Pupil B & $\begin{array}{l}\text { But not like that! Look like this (writes on the } \\
\text { worksheet of V)... }\end{array}$ & Tutoring behaviour (part 1) \\
\hline Pupil V & (interrupts B) No but...(unintelligible) & Unclear utterance (not coded) \\
\hline
\end{tabular}


Pupil B ...look 8.5 centimetres. You have to do it like this, like this (shows by writing on V's worksheet)

Pupil V Is $8 \ldots$

Pupil B No, 8.5.

Pupil V (writes answer down) And this is 10, right?

Pupil B No, we don't have to do that one yet. Just finish this one.

Pupil A Has everyone finished?

Pupil V Almost, just filling in the numbers...
Tutoring behaviour (part 2)*

Low quality constructive

activity

Low quality help

Need for help

- Low quality help

- Organizational utterance (not used in the analyses)

Organizational utterance (not used in the analyses)

Organizational utterance (not used in the analyses)

\footnotetext{
* Coded as a single tutor action. Although the first tutor action is interrupted by the tutee, the utterance of the tutee is unintelligible and the tutor is not distracted by the interruption, continuing the tutor action.
}

\section{References}

Bosker, R. J., \& Guldemond, H. (2004). Een herijking van de gewichtenregeling [A recalibration of the financial arrangements for students with an educational setback]. Groningen, The Netherlands: GION.

Calderón, M., Hertz-Lazarowitz, R., \& Slavin, R. (1998). Effects of bilingual cooperative integrated reading and composition on students making the transition from Spanish to English reading. The Elementary School Journal, 99, 153-165.

Chinn, C. A., O’Donnell, A. M., \& Jinks, T. S. (2000). The structure of discourse in collaborative learning. The Journal of Experimental Education, 69, 77-97.

Cohen, E. G. (1994). Restructuring the classroom: Conditions for productive small groups. Review of Educational Research, 64, 1-35.

DeCarlo, L. T. (1997). On the meaning and use of kurtosis. Psychological Methods, 3, 292307.

Duran, D., \& Monereo, C. (2005). Styles and sequences of cooperative interaction in fixed and reciprocal peer tutoring. Learning and Instruction, 15, 179-199.

Evers, A., Van Vliet-Mulder, J. C., \& Groot, C. J. (2000). COTAN Documentatie van tests en testresearch in Nederland [COTAN Documentation on tests and test research in The Netherlands]. Amsterdam: Boom test uitgevers.

Fuchs, L. S., Fuchs, D., Kazdan, S., \& Allen, S. (1999). Effects of peer-assisted learning strategies in reading with and without training in elaborated help giving. Elementary School Journal, 99, 201-219.

Gill, M. G., Ashton, P. T., \& Algina, J. (2004). Changing preservice teachers' epistemological beliefs about teaching and learning in mathematics: An intervention study. Contemporary Educational Psychology, 29, 164-185.

Gillies, R. M. (2003). Structuring co-operative learning experiences in primary school. In R. M. Gillies \& A. F. Ashman (Eds.), Co-operative learning, the social and intellectual outcomes of learning in groups (pp. 36-53). London: Routledge Falmer.

Gillies, R. M. (2004). The effects of communication training on teachers' and students' verbal behaviours during cooperative learning. International Journal of Educational Research, 41, 257-279.

Gillies, R. M., \& Ashman, A. F. (1997). Children's cooperative behavior and interactions in trained and untrained work groups in regular classrooms. Journal of School Psychology, 35, 261279.

Gillies, R. M., \& Ashman, A. F. (2000). The effects of cooperative learning on pupils with learning difficulties in the lower elementary school. The Journal of Special Education, 34, 19-27. 
Hmelo, C. E., Nagarajan, A., \& Day, R. S. (2000). Effects of high and low prior knowledge on construction of a joint problem space. Journal of Experimental Education, 69, 36-56.

Janssen, J., Kraemer, J. M., \& Noteboom, A. (1996). Rekenen-Wiskunde 3. Handleiding [Arithmetic-Math 3. Manual]. Arnhem, The Netherlands: Citogroep.

Johnson, D. W., \& Johnson, R. T. (1994). Learning together and alone: Cooperative, competitive, and individualistic learning. Englewood Cliffs, NJ: Prentice Hall.

King, A. (2002). Structuring peer interaction to promote high-level cognitive processing. Theory into Practice, 41, 33-39.

Kirchmeyer, C. (1993). Multicultural task groups: An account of the low contribution level of minorities. Small Group Research, 24, 127-148.

Limón, M. (2001). On the cognitive conflict as an instructional strategy for conceptual change: A critical appraisal. Learning and Instruction, 11, 357-380.

Meloth, M. S., \& Deering, P. D. (1999). The role of the teacher in promoting cognitive processing during collaborative learning. In A. M. O’Donnell \& A. King (Eds.), Cognitive perspectives on peer learning (pp. 235-255). Mahwah, NJ: Erlbaum.

Nelson-Le Gall, S., \& Glor-Scheib, S. (1985). Help seeking in elementary classrooms: An observational study. Contemporary Educational Psychology, 10, 58-71.

Newman, R. S., \& Schwager, M. T. (1993). Students' perceptions of the teacher and classmates in relation to reported help seeking in math class. The Elementary School Journal, 94, 317.

Nixon, J. G., \& Topping, K. J. (2001). Emergent writing: The impact of structured peer interaction. Educational Psychology, 21, 41-58.

O'Donnell, A. M., \& Dansereau, D. F. (2000). Interactive effects of prior knowledge and material format on cooperative teaching. Journal of Experimental Education, 68, 101-118.

Oortwijn, M. B., Boekaerts, M., \& Vedder, P. (2005). Is coöperatief rekenen op multiculturele basisscholen effectiever dan klassikaal leren? [Is collaborative learning during math at multiethnic elementary schools more effective than direct teaching?]. Panama-Post, 24, 3-11.

Prichard, J. S., Stratford, R. J., \& Bizo, L. A. (2006). Team-skills training enhances collaborative learning. Learning and Instruction, 16, 256-265.

Pollock, E., Chandler, P, \& Sweller, J. (2002). Assimilating complex information. Learning and Instruction, 12, 61-86.

Puustinen, M. (1998). Help-seeking behavior in a problem-solving situation: Development of self-regulation. European Journal of Psychology of Education, 13, 271-282.

Robinson, D. R., Schofield, J. W., \& Steers-Wentzell, K. L. (2003). Peer and cross-age tutoring in math: Outcomes and their design implications. Educational Psychology Review, 17, 327-362.

Rogoff, B. (1995). Observing sociocultural activity on three planes: Participatory appropriation, guided participation, and apprenticeship. In J. V. Wertsch, P. Del Rio, \& A. Avarez (Eds.), Sociocultural studies of mind (pp. 139-164). New York: Cambridge University Press.

Tesser, P. T. M., \& Iedema, J. (2001). Rapportage Minderheden 2001 [Minorities Report 2001]. Den Haag, The Netherlands: SCP.

Topping, K. J. (2005). Trends in peer learning. Educational Psychology, 25, 631-645.

Topping, K. J, Peter, C., Stephen, P., \& Whale, M. (2004). Cross-age peer tutoring of science in the primary school: Influence on scientific language and thinking. Educational Psychology, 24, 57-75.

Turner, J. C., Meyer, D. K., Cox, K. E., Logan, C., DiCintio, M., \& Thomas, C. T. (1998). Creating contexts for involvement in mathematics. Journal of Educational Psychology, 90, 730-745.

Van Keer, H., \& Verhaeghe, J. P. (2005). Effects of explicit reading strategies instruction and peer tutoring on second and fifth graders' reading comprehension and self-efficacy perceptions. Journal of Experimental Education, 73, 291-329.

Vedder, P. (1985). Cooperative learning: A study on processes and effects of cooperation between primary school children. Groningen, The Netherlands: University of Groningen. 
Vedder, P., \& Horenzcyk, G. (2006). Acculturation and the school. In D. L. Sam \& J. W. Berry (Eds.), Psychology of acculturation; International perspectives (pp. 419-438). Cambridge, UK: Cambridge University Press.

Vedder, P., \& Veendrick, A. (2003). The role of the task and reward structure in cooperative learning. Scandinavian Journal of Educational Research, 47, 529-542.

Webb, N. M., \& Farivar, S. (1994). Promoting helping behavior in cooperative small groups in middle school mathematics. American Educational Research Journal, 31, 369-395.

Webb, N. M., Ing, M., Kersting, N., \& Nemer, K. M. (2006). Help seeking in cooperative learning groups. In S. A. Karabenick \& R. S. Newman (Eds.), Help seeking in academic setting: Goals, groups, and contexts (pp. 45-88). Mahwah, NJ: Erlbaum.

Webb, N. M., \& Mastergeorge, A. M. (2003). The development of students' helping behavior and learning in peer-directed small groups. Cognition and Instruction, 21, 361-428.

Webb, N. M., Nemer, K. M, \& Ing, M. (2006). Small group reflections: Parallels between teacher discourse and student behavior in peer-directed groups. The Journal of the Learning Sciences, 15, 63-119.

Webb, N. M., Troper, J. D., \& Fall, R. (1995). Constructive activity and learning in collaborative small groups. Journal of Educational Psychology, 87, 406-423. 
Table 1

Sample characteristics of the recorded groups

\begin{tabular}{lllll}
\hline Condition & $\begin{array}{l}\text { Number } \\
\text { of groups }\end{array}$ & $\begin{array}{l}\text { Ethnicity (number } \\
\text { of pupils) }\end{array}$ & $\begin{array}{l}\text { Mean mathematical } \\
\text { ability }(\underline{\mathrm{SD}})\end{array}$ & $\begin{array}{l}\text { Mean linguistic } \\
\text { proficiency }(\underline{\mathrm{SD}})\end{array}$ \\
\hline Control & 12 & National $(11)$ & $3.27(1.42)$ & $2.35(.77)$ \\
& & Immigrant $(31)$ & $3.16(1.10)$ & $2.32(.81)$ \\
Experimental & 15 & National $(35)$ & $3.35(1.43)$ & $3.15(.95)$ \\
& & Immigrant $(24)$ & $2.75(1.19)$ & $2.56(.81)$ \\
Total & 27 & 101 & & \\
\hline
\end{tabular}

Table 2

The coding scheme of Webb and Mastergeorge (2003) and the coding scheme used in this study

\begin{tabular}{|c|c|c|c|}
\hline $\begin{array}{l}\text { Webb \& Mastergeorge } \\
(2003)\end{array}$ & Present study & Description & Examples \\
\hline I. Need for help & 1. Need for help & & \\
\hline $\begin{array}{l}\text { Ia. Request for } \\
\text { information }\end{array}$ & $\begin{array}{l}\text { 1a. Asking for an } \\
\text { answer }\end{array}$ & $\begin{array}{l}\text { No intention to ask for an } \\
\text { explanation, typically a } \\
\text { yes/no question }\end{array}$ & L1: This is the area, right? \\
\hline $\begin{array}{l}\text { Ib. Request for } \\
\text { general information }\end{array}$ & $\begin{array}{l}\text { 1b. Request for an } \\
\text { explanation }\end{array}$ & $\begin{array}{l}\text { Typically an open ended } \\
\text { question, that asks for a } \\
\text { process rather an answer }\end{array}$ & $\begin{array}{l}\text { L1: How do you know that's } \\
9 \text { litres? }\end{array}$ \\
\hline $\begin{array}{l}\text { Ic. Request for } \\
\text { specific explanation }\end{array}$ & ------ & & \\
\hline $\begin{array}{l}\text { II. Level of verbally } \\
\text { received help }\end{array}$ & $\begin{array}{l}\text { 2. Level of verbally } \\
\text { provided help* }\end{array}$ & & \\
\hline IIa. Low quality help & 2a. Low quality help & $\begin{array}{l}\text { Help that only includes an } \\
\text { answer / answers }\end{array}$ & $\begin{array}{l}\text { L1: You want to measure } \\
\text { how much is... uh.. is in here. } \\
\text { For instance, in this one there } \\
\text { is } 9 .\end{array}$ \\
\hline IIb. High quality help & 2b. High quality help & $\begin{array}{l}\text { Help that includes an } \\
\text { explanation (with } \\
\text { without answer(s)) }\end{array}$ & $\begin{array}{l}\text { L1: You have to measure the } \\
\text { length and width and then } \\
\text {...uh ... you multiply them. }\end{array}$ \\
\hline $\begin{array}{l}\text { III. Constructive activity } \\
\text { on current problem }\end{array}$ & $\begin{array}{l}\text { 3. Constructive activity on } \\
\text { current problem }\end{array}$ & & \\
\hline $\begin{array}{l}\text { IIIa. Low quality } \\
\text { activity }\end{array}$ & $\begin{array}{l}\text { 3a. } \\
\text { Low } \\
\text { activity }\end{array}$ & $\begin{array}{l}\text { Help application that does } \\
\text { not contain new } \\
\text { information (copying / } \\
\text { finishing } \\
\text { calculation) }\end{array}$ & L1: So it has to do with 6 . \\
\hline $\begin{array}{l}\text { IIIb. High quality } \\
\text { activity }\end{array}$ & $\begin{array}{l}\text { 3b. } \\
\text { High } \\
\text { activity }\end{array}$ & $\begin{array}{l}\text { Help application that } \\
\text { includes new information } \\
\text { (explanation with or } \\
\text { without answer(s)) }\end{array}$ & $\begin{array}{l}\text { L1: Ah, I get it. You multiply } \\
3 \text { with } 2 \text { to get the area. } \\
\text { That's } 6 .\end{array}$ \\
\hline ------ & $\begin{array}{l}\text { 4. Tutor } \\
\text { (unsolicited help) }\end{array}$ & $\begin{array}{l}\text { Utterance targeted at } \\
\text { provoking a problem- } \\
\text { solving response from a } \\
\text { peer }\end{array}$ & $\begin{array}{l}\text { L1: Area is times. So, the } \\
\text { length times the width. That's } \\
\text { the area. So, } 3 \text { times } 2 \text { is? } \\
\text { L2: } 6 \text {. }\end{array}$ \\
\hline $\begin{array}{l}\text { IV. Constructive activity } \\
\text { on next problem }\end{array}$ & ------ & & \\
\hline
\end{tabular}


Table 3

Hierarchical regression analysis of pretest mathematical score, request for an explanation, condition, and ethnicity on posttest mathematical performance

\begin{tabular}{lccccccc}
\hline Variables & $\underline{\mathrm{B}}$ & $\underline{\mathrm{SE}}$ & $\underline{\beta}$ & $\underline{\mathrm{T}}$ & $\underline{\mathrm{F}}$ & $\underline{\mathrm{df}}$ & $\Delta \underline{\mathrm{F}}$ \\
\hline Step 1 & & & & & & $\mathbf{1 , 5 6}$ & \\
$\quad$ Mathematical pretest & .83 & .13 & $.65^{* * *}$ & 6.33 & 40.05 & & \\
Step 2 & & & & & & $\mathbf{2 , 5 5}$ & 5.25 \\
$\quad$ Mathematical pretest & .79 & .13 & $.62^{* * *}$ & 6.22 & 24.17 & & \\
$\quad$ Request for explanation & -.18 & .08 & $-.23^{*}$ & -2.29 & & & \\
$\quad$ Ethnicity & .20 & .36 & .06 & .54 & & & \\
$\quad$ Condition & .17 & .35 & .05 & .49 & & &
\end{tabular}

$\underline{\mathrm{R}^{2}}=.42$ for Step $1 ; \underline{\mathrm{R}^{2}}=.47$ for Step $2 ; \Delta \underline{\mathrm{R}^{2}}=.05(\mathrm{p}<.03)$.

$* \mathrm{p}<.05, * * \mathrm{p}<.01, * * * \mathrm{p}<.001$.

Table 4

Hierarchical regression analysis of pretest mathematical score, tutor actions and ethnicity on posttest mathematical performance

\begin{tabular}{|c|c|c|c|c|c|c|c|}
\hline Variables & $\underline{\mathrm{B}}$ & $\underline{\mathrm{SE}}$ & $\underline{\beta}$ & $\underline{T}$ & $\underline{F}$ & $\underline{\mathrm{df}}$ & $\Delta \underline{\mathrm{F}}$ \\
\hline Step 1 & & & & & 12.58 & 1,25 & \\
\hline Mathematical pretest & .76 & .22 & $.58 * *$ & 3.55 & & & \\
\hline Step 2 & & & & & 10.43 & 2,24 & 5.84 \\
\hline Mathematical pretest & .68 & .20 & $.51 * *$ & 3.39 & & & \\
\hline $\begin{array}{l}\text { Tutor actions provided by } \\
\text { the tutor }\end{array}$ & .05 & .02 & $.37 *$ & 2.42 & & & \\
\hline $\begin{array}{l}\text { Tutor actions received by } \\
\text { the tutee }\end{array}$ & .05 & .05 & .18 & 1.07 & & & \\
\hline Ethnicity & -1.03 & .66 & -.29 & -.95 & & & \\
\hline Condition & -.62 & .65 & -.17 & -1.55 & & & \\
\hline
\end{tabular}

Table 5

Regression analyses of the interaction of mathematical ability and condition, and of ethnicity and mathematical ability at the individual level on the categories of the coding scheme

\begin{tabular}{|c|c|c|c|c|c|c|c|c|}
\hline \multirow[b]{2}{*}{ Category } & \multirow[b]{2}{*}{$\underline{F}$} & \multirow[b]{2}{*}{$\underline{\mathrm{df}}$} & \multirow[b]{2}{*}{$\underline{\mathrm{R}^{2}}$} & \multirow[b]{2}{*}{$\underline{\mathrm{n}}$} & \multicolumn{2}{|c|}{$\begin{array}{l}\text { Condition } \mathrm{x} \\
\text { Mathematical ability }\end{array}$} & \multicolumn{2}{|c|}{$\begin{array}{l}\text { Ethnicity } \mathrm{x} \\
\text { Mathematical ability }\end{array}$} \\
\hline & & & & & $\underline{T}$ & $\underline{\beta}$ & $\underline{T}$ & $\underline{\beta}$ \\
\hline \multicolumn{9}{|l|}{ 1. Need for help } \\
\hline 1a. Request for answer & 2.33 & 2,90 & .12 & 92 & -2.27 & -.25 & -.83 & -.09 \\
\hline 1b. Request for explanation & .49 & 2,56 & .04 & 58 & -.15 & -.02 & -1.09 & -.15 \\
\hline \multicolumn{9}{|l|}{ 2. Verbally provided help } \\
\hline 2a. Low quality help & 2.07 & 2,94 & .04 & 96 & -1.94 & -.21 & -1.19 & -.13 \\
\hline 2b. High quality help & 4.17 & 2,41 & .17 & 43 & -1.67 & -.25 & $-2.79 *$ & -.42 \\
\hline \multicolumn{9}{|l|}{$\begin{array}{l}\text { 3. Constructive activity on } \\
\text { current problem }\end{array}$} \\
\hline 3a. Low quality activity & 7.81 & 2,65 & .19 & 67 & -2.39 & -.29 & $-3.08 *$ & -.36 \\
\hline 3b. High quality activity & 3.35 & 2,38 & .33 & 40 & -2.29 & -.37 & -2.03 & -.33 \\
\hline 4. Tutor actions & .90 & 2,24 & .18 & 26 & -.21 & -.05 & -1.01 & -.26 \\
\hline
\end{tabular}


Figure 1. Mean individual low quality help provided by national pupils $(\underline{\mathrm{n}}=45)$ and immigrant pupils $(\underline{\mathrm{n}}=56)$, corrected for mathematical ability in the control and the experimental condition.

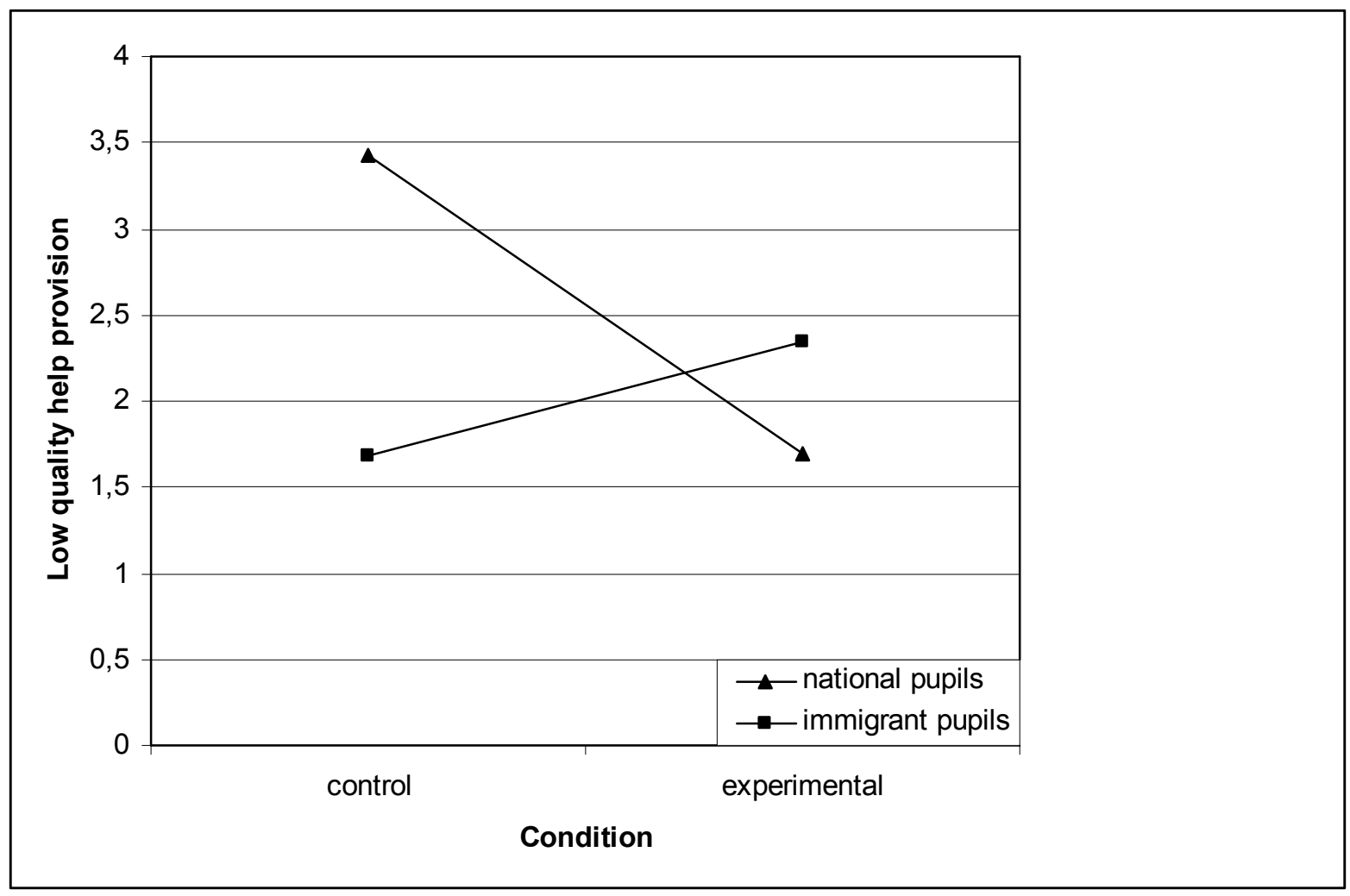

